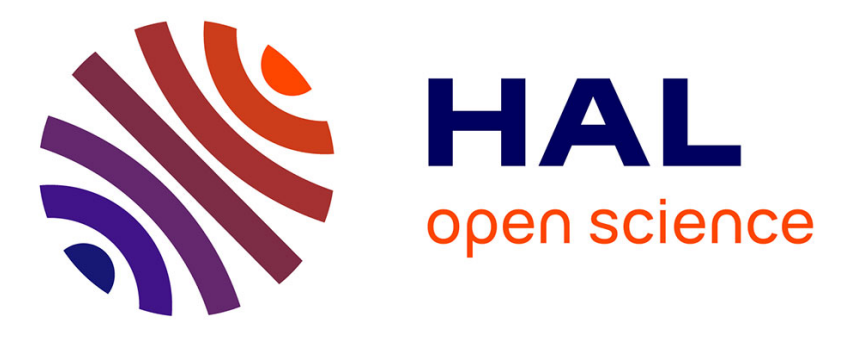

\title{
Using 3D reconstructions of centimeter-scale sedimentary structures to document changes in the depositional settings of Glen Torridon region (Gale crater, Mars)
}

Gwénaël Caravaca, Nicolas Mangold, Laetitia Le Deit, Stéphane Le Mouélic, Erwin Dehouck, Olivier Gasnault, Kenneth Edgett, Frances

Rivera-Hernández, Christoher M Fedo, Roger Wiens

\section{- To cite this version:}

Gwénaël Caravaca, Nicolas Mangold, Laetitia Le Deit, Stéphane Le Mouélic, Erwin Dehouck, et al.. Using 3D reconstructions of centimeter-scale sedimentary structures to document changes in the depositional settings of Glen Torridon region (Gale crater, Mars). Europlanet Science Congress 2020, Sep 2020, Online, Germany. 10.5194/epsc2020-49 . hal-02933166

\section{HAL Id: hal-02933166 https://hal.science/hal-02933166}

Submitted on 8 Sep 2020

HAL is a multi-disciplinary open access archive for the deposit and dissemination of scientific research documents, whether they are published or not. The documents may come from teaching and research institutions in France or abroad, or from public or private research centers.
L'archive ouverte pluridisciplinaire HAL, est destinée au dépôt et à la diffusion de documents scientifiques de niveau recherche, publiés ou non, émanant des établissements d'enseignement et de recherche français ou étrangers, des laboratoires publics ou privés.

\section{(c)(1)}

Distributed under a Creative Commons Attribution| 4.0 International License 


\title{
Using 3D reconstructions of centimeter-scale sedimentary structures to document changes in the depositional settings of Glen Torridon region (Gale crater, Mars)
}

\author{
Gwénaël Caravaca ${ }^{1}$, Nicolas Mangold ${ }^{1}$, Laetitia Le Deit ${ }^{1}$, Stéphane Le Mouélic ${ }^{1}$, Erwin Dehouck ${ }^{2}$, \\ Olivier Gasnault ${ }^{3}$, Kenneth S. Edgett ${ }^{4}$, Frances Rivera-Hernández ${ }^{5}$, Christoher M. Fedo ${ }^{6}$, and Roger \\ C. Wiens ${ }^{7}$ \\ ${ }^{1}$ CNRS, UMR 6112 CNRS Laboratoire de Planétologie et Géodynamique Nantes, Nantes, France (gwenael.caravaca@univ- \\ nantes.fr) \\ ${ }^{2}$ UMR 5276 Laboratoire de Géologie de Lyon, Terre Planètes Environnement, Univ Lyon, Université Claude Bernard Lyon 1, Lyon, \\ France \\ ${ }^{3}$ UMR 5277 Institut de Recherche en Astrophysique et Planétologie, Université Paul Sabatier Toulouse III, Toulouse, France \\ ${ }^{4}$ Malin Space Science Systems, San Diego, CA, USA \\ ${ }^{5}$ Dept. of Earth Sciences, Darthmouth College, Hanover, NH, USA \\ ${ }^{6}$ Dept of Earth and Planetary Sciences, University of Tenessee, Knoxville, TN, USA \\ ${ }^{7}$ Space and Atmospheric Science Division, Los Alamos National Laboratory, Los Alamos, NM, USA
}

Introduction: The Glen Torridon (GT) region in Gale crater, has been explored using the Mars Science Laboratory rover, Curiosity, since January 2019 ( Sol 2300) to document clay-bearing rocks initially detected via orbiter data [1]. The rocks are part of the Murray formation, with lower GT consisting of the Jura member mudstones generally associated with a lacustrine deposition [2] overlain by laminated and cross-bedded fine-grained sandstones of the Knockfarril Hill (KfH) member. The latter hint at a sharp change in depositional environment that is critical to investigate [2]. To that extent, we use high-resolution photogrammetric micro-Digital Outcrop Models (DOM) to characterize centimeter-scale sedimentary structures in the $\mathrm{KfH}$ member to shed light on their implications in terms of depositional settings and dynamics.

\footnotetext{
Micro-Digital Outcrop Models (DOM) production using Structure-from-Motion photogrammetry: The MArs Hand Lens Imager (MAHLI) instrument is a color micro-imager on the rover's robotic arm, able to distinguish coarse silt at a distance of $\sim 2$ to $4 \mathrm{~cm}$ [3]. MAHLI provides close-up perspectives on rock outcrops and individual targets, notably to assess grain size distribution and sub-mm- to $\mathrm{cm}$-scale sedimentary structures. MAHLI photo mosaics of rock faces typically have sufficient overlapping frames to apply Structure-from-Motion photogrammetry to create 3D micro-DOMs (e.g. [4]). These high-resolution, accurate 3D representations can help us distinguishing sedimentary versus deformational structures from erosional features. Micro-DOMs also enable observation of the outcrop from varying points of view to characterize 3D structures and their lateral/vertical variations. This is especially important in the $\mathrm{KfH}$ member due to the very finegrained nature of the observed sandstones, with $\mathrm{cm}$-scale variations in the sedimentary architecture potentially indicative of rapid shifts in laterally evolving depositional settings. Understanding the nature of the rocks at this scale is also helpful to interpret the chemistry data obtained by the
} 
ChemCam instrument from the submillimeter scale (one measurement point) to the centimeter scale (between the points).

Characterization of 3D centimeter-scale sedimentary structures: Here, we focus on three outcrops that exhibit key characteristics of the $\mathrm{KfH}$ member of the Murray formation: Morningside (Fig. 1), Stack_of_Glencoul (Fig. 2) and Strathdon (Fig. 3).

Morningside (Sol 2424, Fig. 1a) is part of an outcrop called Woodland Bay. It exposes a $\sim 45$ by $\sim 25$ $\mathrm{cm}$ patch of fine-grained sandstone that, we think, interfingers with surrounding Jura member mudstones. Morningside exhibits a conspicuous alternation of finely-laminated (mm-scale) and more massive $\mathrm{cm}$-scale beds of fine sandstones. Both the beds and their inner laminations display crossstratifications with varying directions of propagation (blue lines, Fig. 1b), separated by truncation surfaces (red lines, Fig. 1b). Interestingly, the more massive beds do not appear to result from a potential grading but are rather due to differential resistance to erosion. These structures indicate deposition under moderate but sustained fluvial hydrodynamical flow rather than a quiet lacustrine setting.
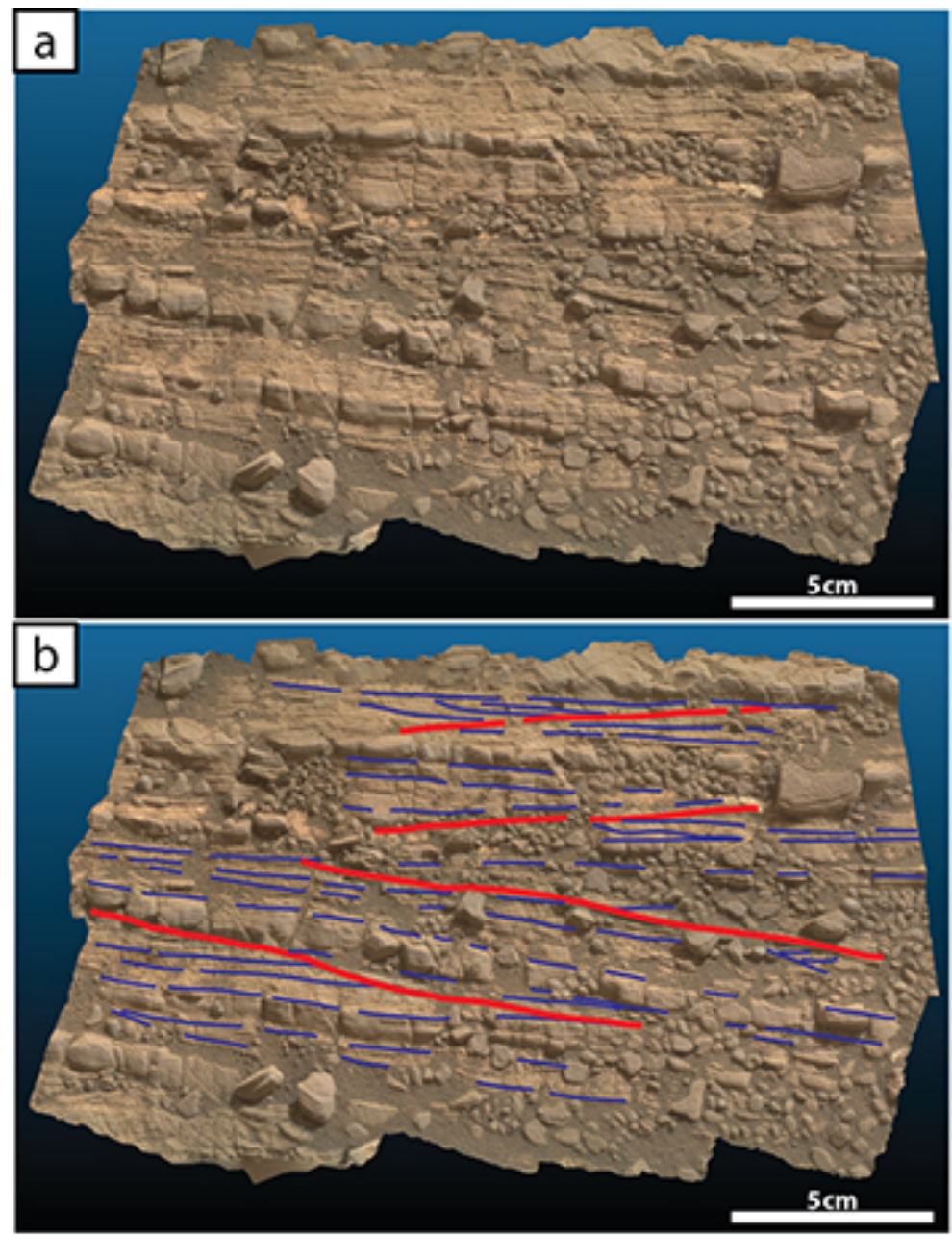

Fig. 1 a) 3D micro-DOM of the Morningside target (Sol 2424, https//skfbly/6SE7y). b) Interpretation of the same view as; blue lines: cross-stratifications; red lines: truncations.

Stack_of_Glencoul (Sol 2444, Fig. 2a) is part of the Teal Ridge outcrop. It displays mm-scale laminations (blue lines, Fig. 2b) arranged in at least four sets of low angle $\left(<15^{\circ}\right) \mathrm{cm}$-scale crossstratifications, separated by sharp truncation surfaces (red lines, Fig. $2 \mathrm{~b}$ ). These truncations and 
multiple/alternating directions of propagation in 3D (Fig. 2b) suggest deposition in a dynamic setting such as a fluvial environment. We also observe traces of a complex post-depositional history as indicated by a network of diagenetic veins (some cross-cutting the laminations, others occurring between layers, Fig. 2), identified by ChemCam as calcium sulfate veins (similar to those identified throughout the Murray formation; [5]).
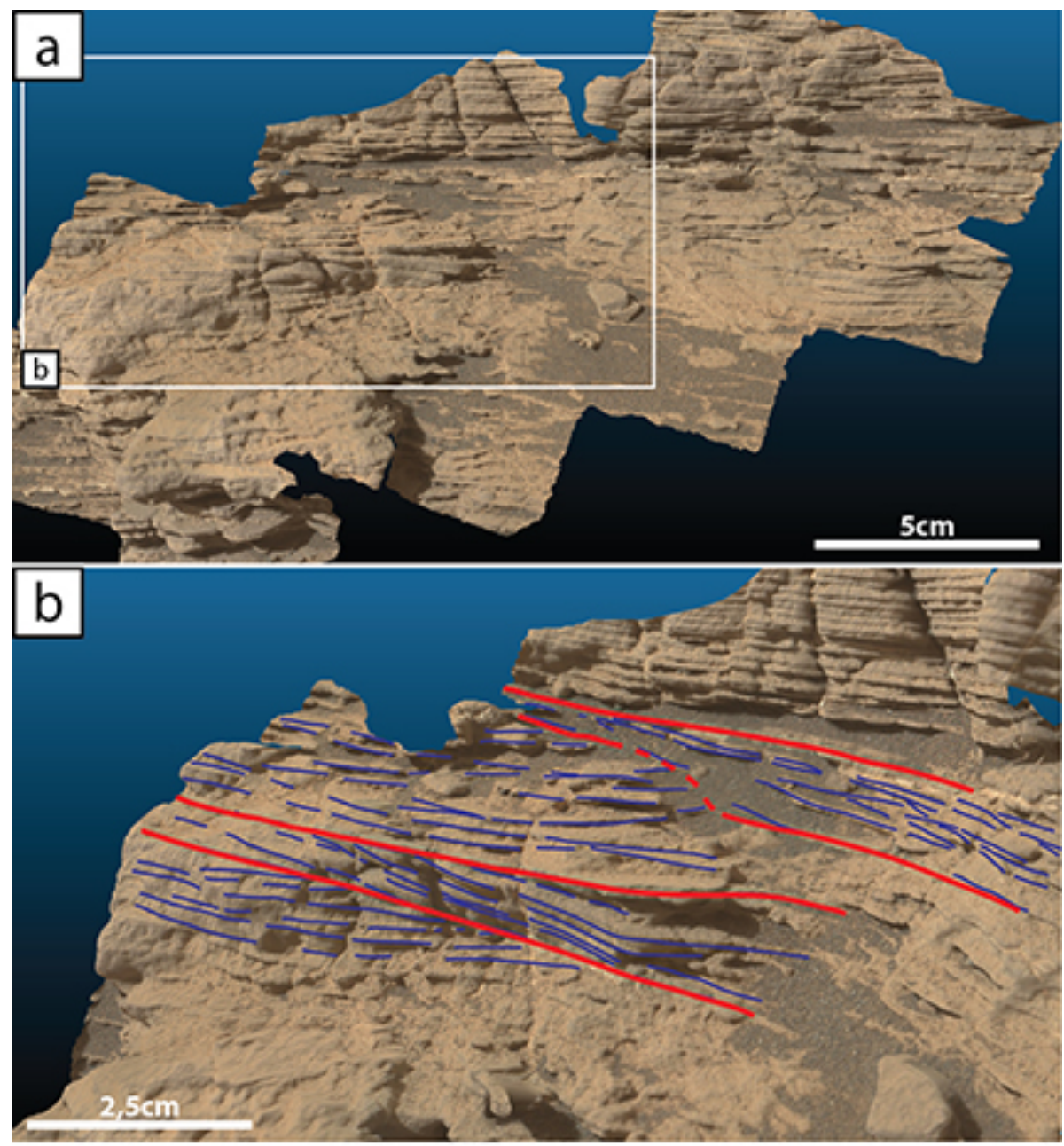

Fig. 2a) 3D micro-DOM of the Stack_of_Glencoul target (Sol 2444) reconstructed using 15 MAHLI images (https://skfb.ly/6P72S). b) Close-up view and interpretation of cross-stratification structures from a different point of view; blue lines: cross-stratifications; red lines; truncations.

Strathdon (Sol 2462, Fig. 3a) shows sub-cm-scale undulating laminations, highlighted by differential erosion of the outcrop. While these undulations could be ripple marks, burial can also create similar structures [e.g. 6]. Nevertheless, these laminations are characterized by cm-scale crossstratifications with varying directions of propagation (green lines, Fig. 3b), suggesting an energetic fluvial setting during deposition. In the lower part of the outcrop, undulated laminations are unconformably lying on a more massive bed (red line, Fig. 3b). This contact hints at potentially rapid fluctuations of the hydrodynamical regime between quieter and more energetic settings. Similar to the Stack_of_Glencoul target, Strathdon also displays a network of calcium sulfate veins. 

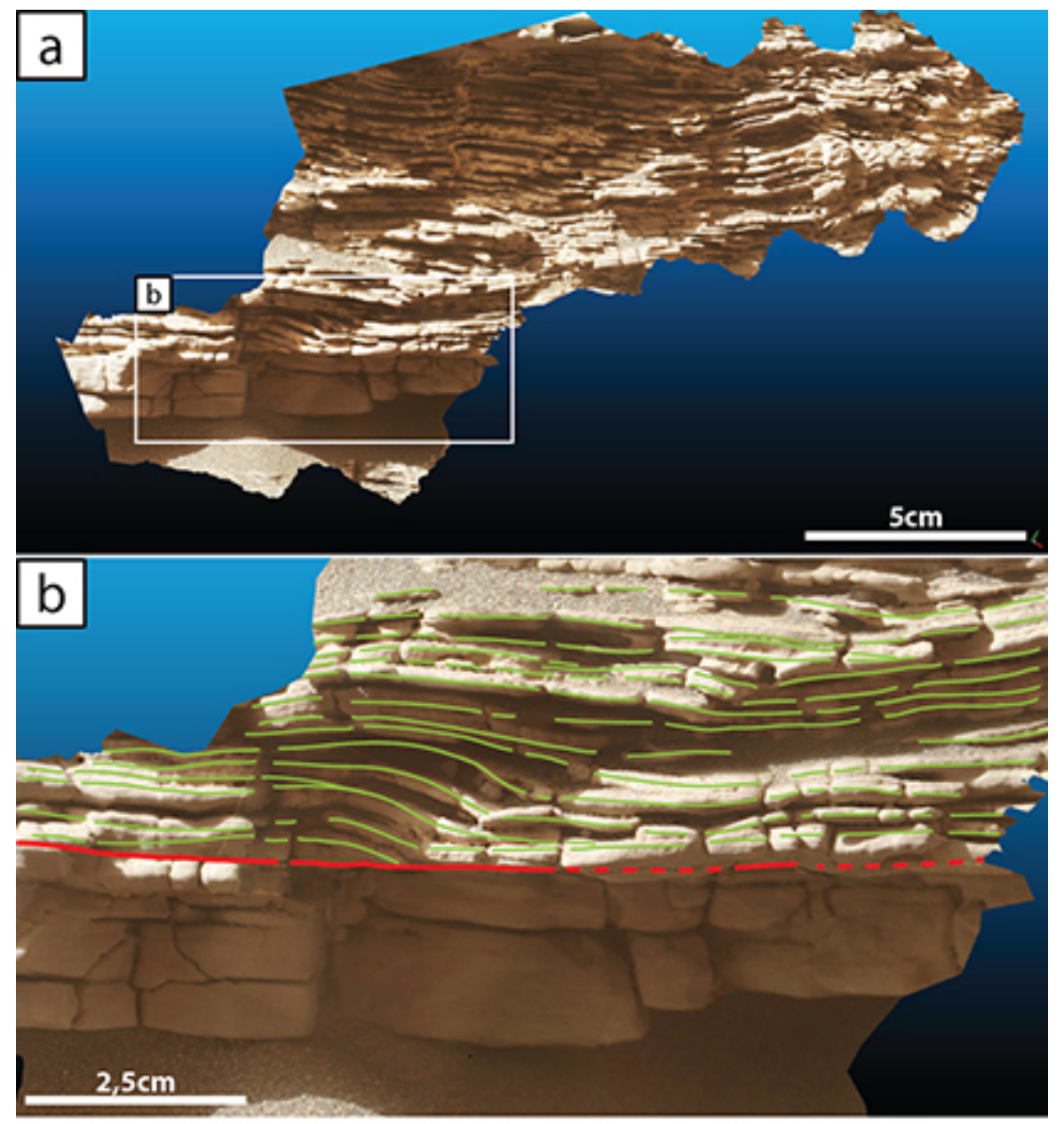

Fig, 3 a) 3D micro-DOM of the Stathdon target (Sol 2462) reconstructed using 18 MAHLI images (https://skfb.ly/6P7tz). b) Close-up view and interpretation of different sets of cross-stratifications from a different point of view. Green lines: cross-stratifications; red line: unconformable contact (dashed lines denote parts of the contact hidden under an overlying lamination).

Summary and future work: The production of high-resolution 3D micro-DOMs of centimeter-scale sedimentary structures based on MAHLI images proves to be useful to accurately identify and characterize these structures at a fine scale in the GT region. This is particularly important to assess the rapid lateral and vertical variations of the depositional setting as recorded in the Knockfarril Hill member of the Murray formation. Indeed, the cross-stratifications observed here within the fine sandstones of these outcrops indicate a progressive shift from quiet lacustrine environments of the underlying Jura member, towards a more dynamic fluviatile depositional setting.

These changes (through time and space) might have critical implications regarding the deposition and/or in situ formation of the clay-bearing rocks that are characteristic of the GT region. The documentation of the associated local geochemistry (notably in alkali elements), as documented by the ChemCam instrument, will be integrated in further work to assess whether the geochemical record varies in line with the sedimentary record.

Acknowledgments: EU H2020 PlanMap project. 
References: [1] Milliken, R.E. et al. (2010) Geophys Res Lett, 3, L04201. [2] Fedo, C.M. et al. (2020) LPSC abstract \#2345. [3] Edgett, K.S. et al. (2015) MSL MAHLI Technical Report 0001, Version 2. [4] Caravaca, G. et al. (2020) Planet Space Sci, 182, 104808. [5] L'Haridon, J. et al. (2018) Icarus, 311, 69-86. [6] Alexander, J. (1987) Geol. Soc. SP, 29, 315-324 